\title{
EFFECT OF NICOTINE ON THE MOTILITY OF THE OVIDUCTS IN THE RHESUS MONKEY: A PRELIMINARY REPORT
}

\author{
A. NERI* AND S. L. MARCUS \\ Department of Obstetrics and Gynecology, \\ Cornell University Medical College, New York, N.Y. 10021, U.S.A.
}

(Received 1st September 1971, accepted 26th Fanuary 1972)

\begin{abstract}
Summary. Tubal activity under the influence of nicotine was studied in vivo in six mature rhesus monkeys throughout the various phases of the menstrual cycle, using an open-ended catheter technique. The activity monitoring response during the first half of the menstrual cycle was of two types, an early and a delayed response. The first was of higher tone and amplitude, and the second was followed within 1 to 2 min by complete inhibition of tubal activity which lasted for the next 5 to 30 min. During the second half of the menstrual cycle, intravenous nicotine had no significant effect on tubal tonus and the amplitude was only slightly and occasionally affected. The possible mechanism of action of nicotine, both direct and indirect, on tubal activity is discussed.
\end{abstract}

\section{INTRODUCTION}

A change in uterotubal movement may interfere with the mechanisms of ovum pick-up, migration, fertilization, transfer through the uterotubal junction into the uterine cavity, or implantation, and thus affect fertility. In view of previous studies in which the inhalation of cigarette smoke was found to have an effect on uterotubal junction activity (Neri \& Eckerling, 1969), it was decided to investigate the influence of nicotine on tubal activity in vivo in rhesus monkeys, Macaca mulatta. Monkeys were used since they are the only laboratory animals that have reproductive processes sufficiently similar to those of human beings.

In the present study, the tubal motility under the influence of nicotine was determined by recording the intraluminal pressure changes during the menstrual cycle.

\section{MATERIALS AND METHODS}

Six rhesus monkeys, weighing 4 to $6 \mathrm{~kg}$, were selected for this investigation. The monkeys were fully mature and had had at least three regular menstruations before the start of the investigation. The menstrual cycles were monitored by vaginal cytology every 2 days (using the criteria of de Allende, Shorr \& Hartman, 1945) and by weekly plasma progesterone determinations using a competitive protein-binding method.

* Present address: Department of Obstetrics and Gynecology, Beilinson Hospital, Tel Aviv University Medical School, Petah Tikva, Israel. 
Phencyclidine hydrochloride (Sernylan-Parke, Davis and Company, Detroit, Michigan) was given intramuscularly $(1.0 \mathrm{mg})$ to the monkeys before removing them from their cages. Infusion of Diabutal TM (sodium pentobarbitone) in dextrose $5 \%$ was given slowly intravenously in a minimal dose of 3 to $4 \mathrm{mg} / \mathrm{kg} / \mathrm{hr}$, to keep the animals quiet without pain or movement during the procedures.

Fallopian tube activity was evaluated by the open-ended catheter technique. The fenestrated tip of a teflon tube (No. 6439 thin wall, $0.034 \times 0.058$ in., Becton, Dickinson and Company, Rutherford, N.J.) was inserted at laparotomy into the ampullary part of the tubes through their fimbrial ends. The fimbrial and isthmic ends were then closed, using No. 00000 silk. The external end of the teflon tube was delivered through a small paramedian incision in the abdominal wall and secured in place by No. 000 silk to the abdominal fascia. Tubal activity was recorded by connecting the external end of the teflon tube (filled with heparinized saline) to a pressure transducer (model 267 BC, Sanborn Company) which transmitted the impulses to a 321 Dual Channel Carrier AmplifierRecorder (Hewlett-Packard). The first recording was made on the day of the laparotomy (after the abdominal incision had been closed). The external end of the teflon tube was not sealed but covered with a sterile dressing to allow subsequent recordings to be made. The technique was the same as that used in our previous investigations (Neri, Marcus \& Fuchs, 1972). Tubal activity was recorded over a period of 4 to $8 \mathrm{hr}$ from twice weekly to once daily during the menstrual cycle. A total of fifty-two tests was performed on these six monkeys.

The amount of nicotine (nicotine hydrogen tartrate) used in the investigation was from 0.2 to $0.3 \mathrm{mg}$, as a $1: 1000$ solution in normal saline, or $0.05 \mathrm{mg} / \mathrm{kg}$ body weight of the monkeys.

\section{RESULTS}

Before the administration of nicotine, the recordings of spontaneous Fallopian tube intraluminal pressure changes revealed a pattern consisting of relatively small contractions as well as outbursts of contractions of greater amplitude at fairly regular intervals.

The tubal activity responded to the intravenous injections of nicotine within a few seconds, the response being of two types, an early and a delayed one. These changes in tubal activity were particularly evident in the first half of the menstrual cycle (Text-figs 1 to 9 ). As in previous communications, we have divided the menstrual cycle as follows: menstruation-Days 1 to 4 , early follicular phase-Days 5 to 8 , mid-proliferative phase-Days 9 to 12, ovulatory phaseDays 13 to 16 , mid-secretory phase-Days 17 to 22 , late secretory phaseDays 23 to 31 . The monitored contractile responses during this period of the menstrual cycle immediately showed elevated tone $(5$ to $10 \mathrm{~mm} \mathrm{Hg}$, lasting from $30 \mathrm{sec}$ to $3 \mathrm{~min}$ ) and higher amplitudes ( 3 to $6 \mathrm{~mm} \mathrm{Hg}$, lasting 1 to $3 \mathrm{~min}$ ). Following this, for the next 5 to $30 \mathrm{~min}$, there was almost complete inhibition of tubal activity. By contrast, during the second half of the menstrual cycle, no significant change occurred in tubal tonus after nicotine, and the amplitude was only slightly and occasionally affected. The frequency of bursts, however, 
Text-pigs 1 to 9. Patterns of tubal motility on various days of the menstrual cycle in the rhesus monkey, with the effect of intravenous injection of nicotine hydrogen tartrate $(0.05 \mathrm{mg} / \mathrm{kg}$ body $\mathrm{wt})$. Note the striking changes in tubal activity after nicotine, which are particularly marked in the first half of the menstrual cycle.

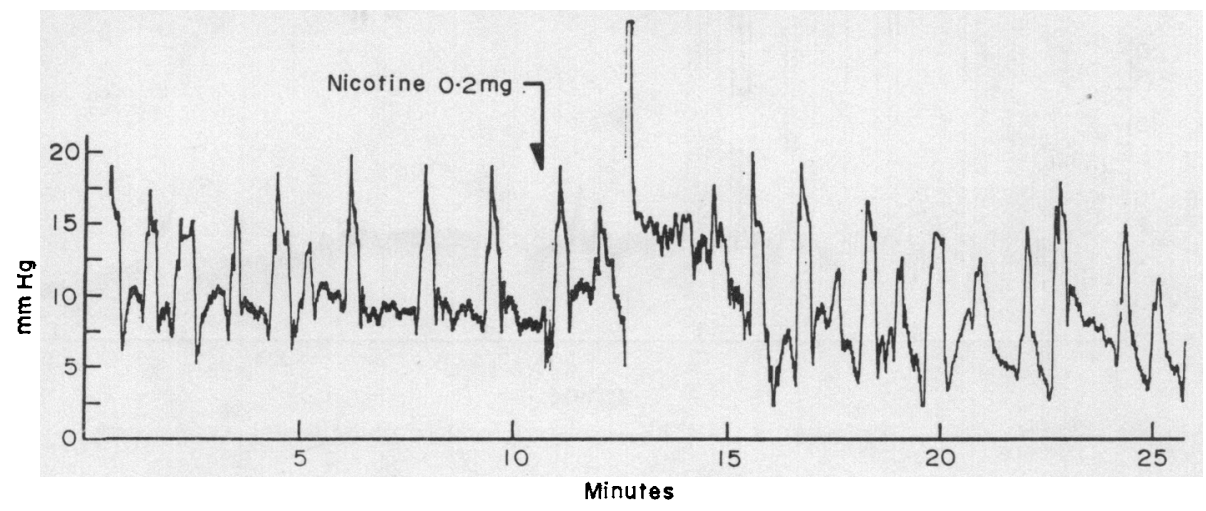

Text-Fig. 1. Day 1-menstruation.

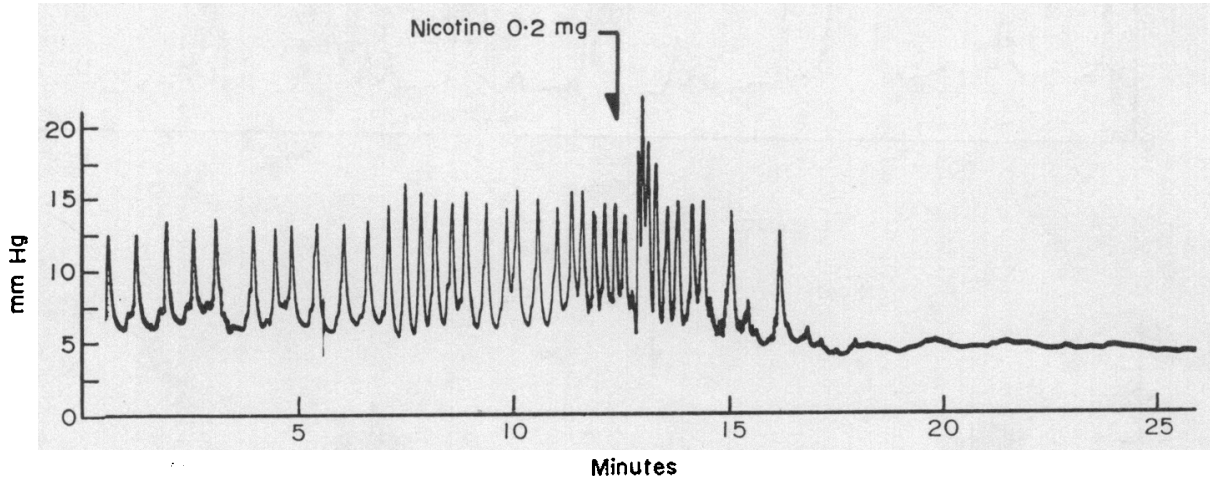

Text-Fig. 2. Day 9-mid-proliferative phase.

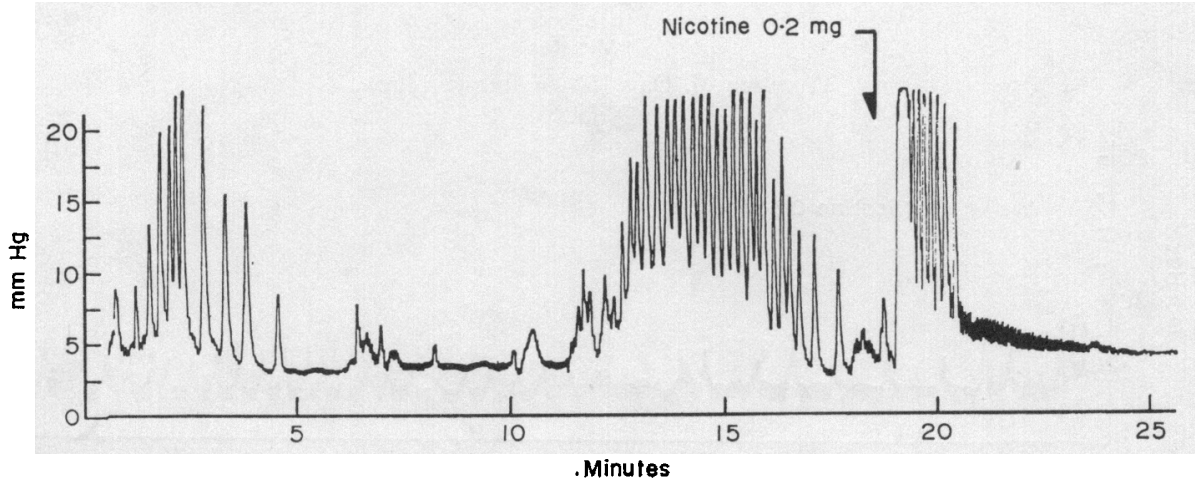

TEXT-FIG. 3. Day 10-mid-proliferative phase. 


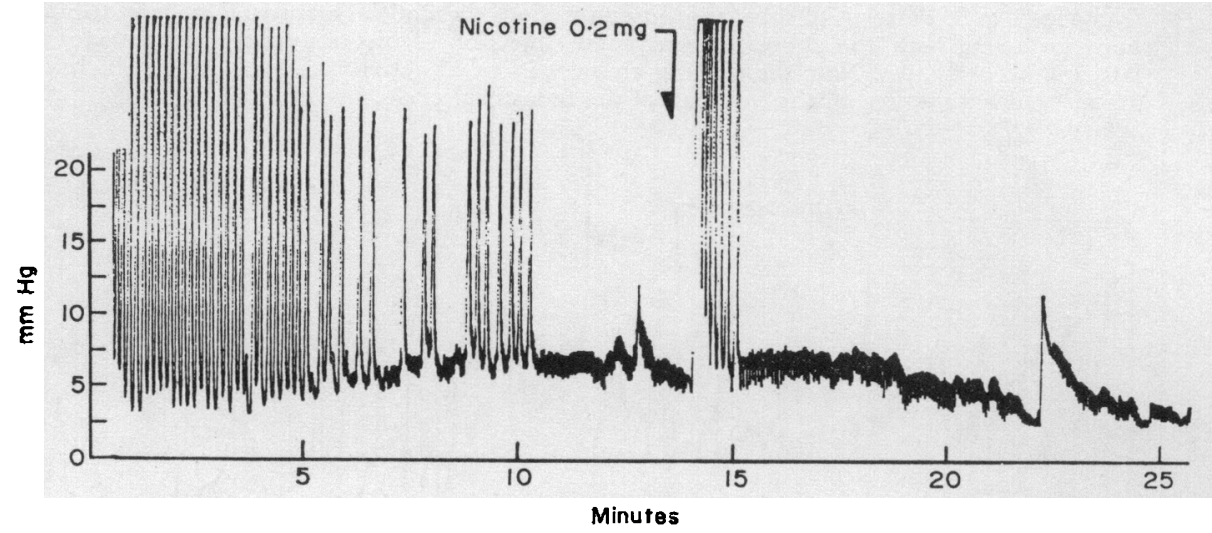

TeXT-Fig. 4. Day 11-mid-proliferative phase.

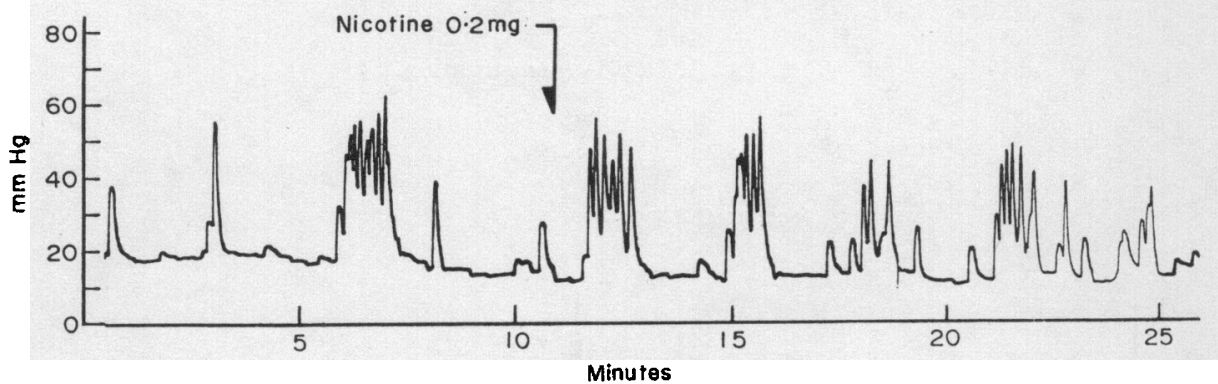

Text-Fig. 5. Day I4-ovulatory phase.

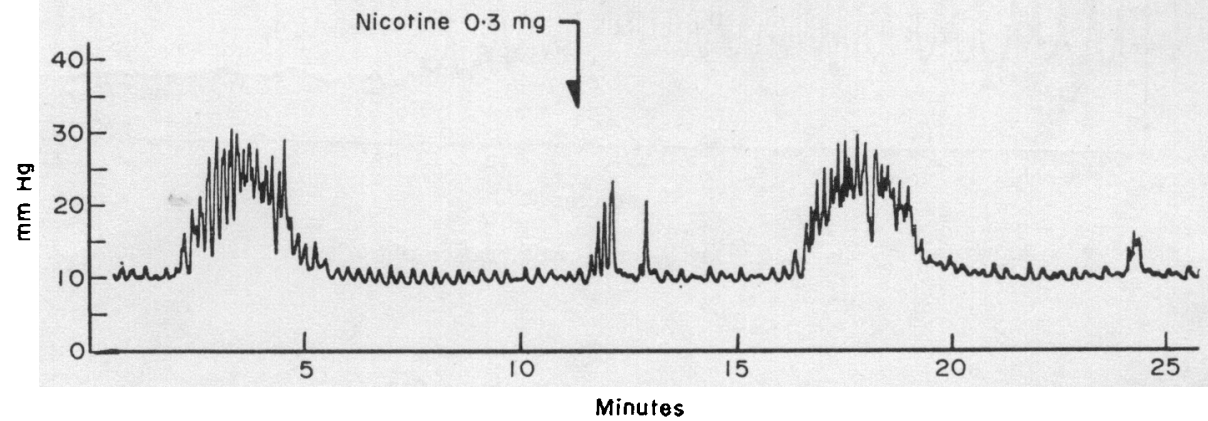

Text-rig. 6. Day 15-ovulatory phase.

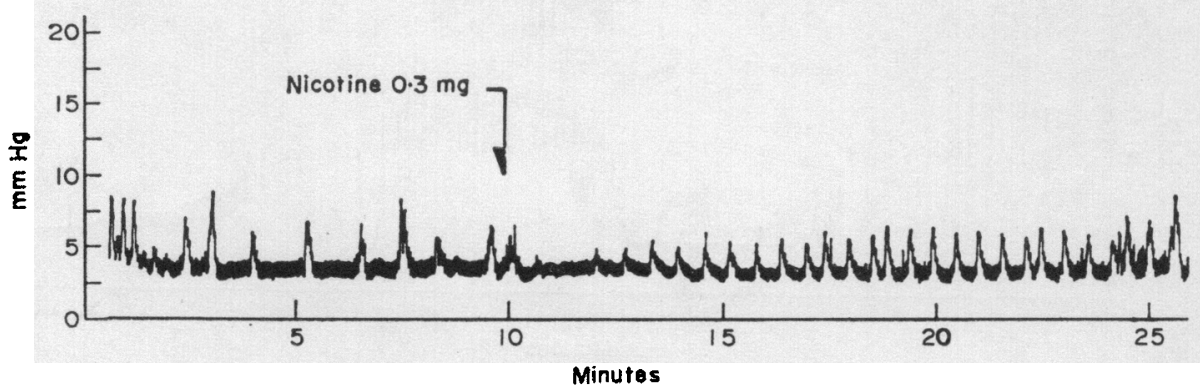

TeXT-Fig. 7. Day 17-mid-secretory phase. 


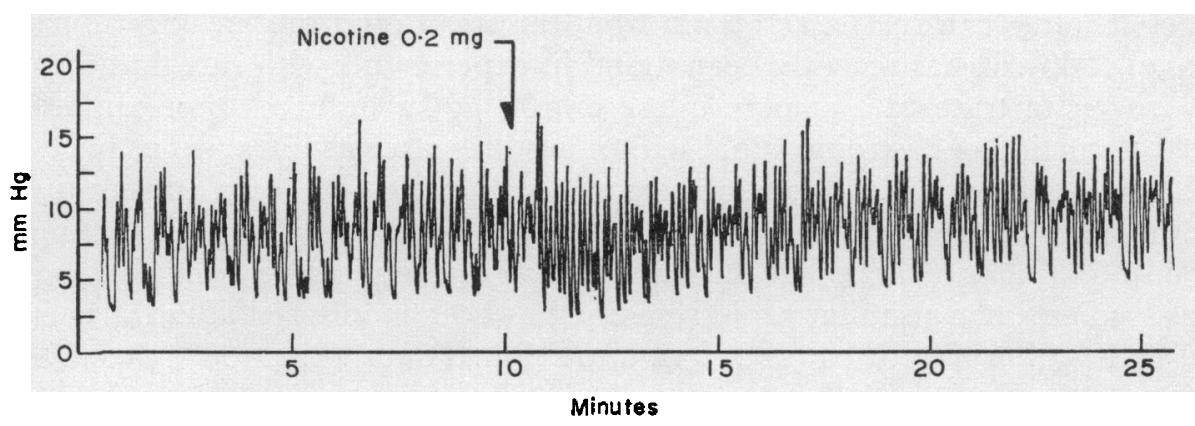

Text-Fig. 8. Day 22-mid-secretory phase.

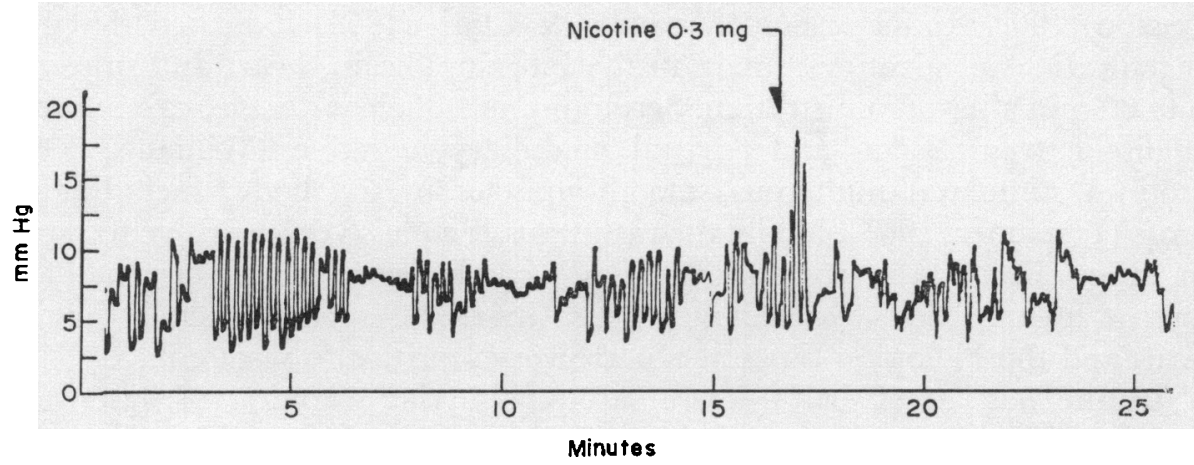

TeXt-Fig. 9. Day 26-late secretory phase.

was increased. During the ovulatory phase, the only change was an increased frequency of contractile bursts. Occasionally, there was a slight increase in amplitude but it was usually unaffected. The immediate responses in the midsecretory phase were a slight elevation of tonus ( 3 to $5 \mathrm{~mm} \mathrm{Hg}$ ), no change in the amplitude of the contractions and, at a later stage, inhibition of tubal activity (for 3 to $5 \mathrm{~min}$ ) in four of the six monkeys. The only changes of tubal activity in the later secretory phase were larger amplitudes of contractions (lasting 1 to $3 \mathrm{~min}$ ).

\section{DISGUSSION}

Nicotine has been shown to have a deleterious effect upon reproduction in experimental animals (Bernhard, 1948), and cigarette smoke inhalation is known to have an effect on the uterotubal activity in the human (Neri \& Eckerling, 1969). This fact was attributed mainly to the nicotine effect on the adrenal medulla and on other chromaffin cells outside the medulla which secrete adrenaline. Recent study of the effect of epinephrine on tubal activity in vivo has shown that epinephrine has a stimulatory effect on the human Fallopian tube, except during the luteal phase, when the response of the tube appears to be diminished and altered in character (Coutinho, Maia \& Filko, 1970).

Nicotine is believed to exert its major effect on autonomic ganglia and, in the intestine, this involves release of acetylcholine at parasympathetic synapses. 
Acetylcholine can release serotonin from the small intestines in dogs (Burks \& Long, 1966). It has recently been found in experiments with rats that nicotine hydrogen tartrate in a smoking dose of $100 \mu \mathrm{g} / \mathrm{kg}$ induced approximately a $40 \%$ depletion of gastrointestinal serotonin stores after its intravenous injection. The maximal serotonin depletion occurred within 20 to $30 \mathrm{sec}$ of administration with return to control values by 10 to $30 \mathrm{~min}$ (Thompson, Spezia \& Angulo, 1969). This fact will explain the rapid action of the nicotine administration in our studies, since a similar rapid response has been monitored after intravenous administration of serotonin (A. Neri, unpublished data). Since $90 \%$ (5 to $10 \mathrm{mg}$ ) of the serotonin stores in human body (Williams, 1965) are in the intestines, even a small stimulation (cf. the dose of $50 \mu \mathrm{g}$ nicotine hydrogen tartrate $/ \mathrm{kg}$ given in this study) will cause appreciable depletion of these stores into the circulation. Hansson (1964) and Hansson, Masouko \& Clark (1964) indicated that high concentrations of nicotine remain in the intestine, brain, heart and spleen for up to $60 \mathrm{~min}$ after administration. Serotonin, in sufficient dosage, can influence ganglionic transmission and adrenal medullary secretion (Williams, 1965). Serotinin stimulates numerous smooth muscles in the body, including the uterus (Erspamer, 1961). While the rat uterus in vitro is very sensitive to serotonin, strips of human uterus under the same conditions are not (Garrett, 1958). Current investigations carried out by us in rhesus monkeys show that the uterus and the Fallopian tubes in vivo are very sensitive to serotonin.

Nicotine has an effect on the neurohypophysial secretion of vasopressin (antidiuretic hormone) (Burn, Truelove \& Burn, 1945; Bissett \& Walker, 1957; Bissett \& Lee, 1958; Caldeyro-Barcia \& Heller, 1961) and probably increases the secretion of oxytocin (Bissett \& Walker, 1957). Antidiuresis is elicited in normal subjects by making them inhale the smoke of one or more cigarettes or by injecting nicotine intraveneously (Burn et al., 1945; Walker, 1949; Taylor \& Walker, 1951; Caldeyro-Barcia \& Heller, 1961). The amount of vasopressin recovered from human urine, according to various investigations, ranges from 3 to $259 \mu \mathrm{U}$ vasopressin (Burn \& Grewal, 1951; Taylor \& Walker, 1951; Bissett \& Lee, 1958). The dissociation in the levels of oxytocin and vasopressin observed in different experiments (as after intravenous administration of nicotine) suggests that under certain conditions these hormones may be released independently from the neurohypophysis (Caldeyro-Barcia \& Heller, 1961). The situation is complicated by the fact that adrenaline, which is secreted as a response to the stimulation of the nicotine injection, produces some degree of inhibition of vasopressin release (Dyball, 1968).

Intravenous injection of nicotine to human beings usually causes unpleasant side-effects which last for a few minutes. These range from slight dizziness and paraesthesiae to intense hyperpnoea, flushing, palpitation and a feeling of constriction in the chest, followed by pallor and sweating. A brief initial rise in blood pressure after nicotine injection may be followed by a transient fall lasting a few minutes (Williams, 1965). Fortunately, the only side-effects seen in two of our monkeys following the intravenous administration of the nicotine were pallor and fine tremor lasting for a few minutes. In four of the monkeys, in which a femoral artery cannula was used, no change in blood pressure was noticed. 
Current investigations in rhesus monkeys in vivo (A. Neri, unpublished data) show the Fallopian tube to be sensitive to the intravenous administration of oxytocin, vasopressin and epinephrine. The results in every case have depended on the amount of the drug, the menstrual phase and environmental factors. Nicotine was also found to have an effect on tubal activity in experiments in vitro.

The data collected in this and previous studies (Neri \& Eckerling, 1969) point to a possible effect of nicotine and adrenaline on tubal motility. Since the time which it takes for the fertilized ovum to reach the uterine cavity is such an important factor, any change may act to prevent implantation and thus influence fertility. As noted before, this effect may be attributed to the nicotine itself or to resultant changes taking place in the body.

\section{AGKNOWLEDGMENTS}

Appreciation is expressed to Professor Fritz Fuchs for his encouragement and helpful discussions. This work was supported by Grant $67-455$ from the Ford Foundation.

\section{REFERENCES}

Bernhard, P. (1948) The influence of cigarette smoking on pregnancy. Zentbl. Gynäk. 70, 18.

BISSETT, G. W. \& LEE, J. (1958) Antidiuretic activity in the blood after stimulation of the neurohypophysis in man. Lancet, $\mathbf{i i}, 715$.

Bissett, G. W. \& Walker, J. M. (1957) The effects of nicotine hexamethonium and ethanol on the secretion of anti-diuretic and oxytoxic hormones of the rat. Br. F. Pharmac. Chemother. 12, 461.

Burks, T. F. \& Long, J. P. (1966) 5-Hydroxytryptamine release into dog intestinal vasculature. Am. F. Physiol. 211, 619.

Burn, G. P. \& Grewal, R. S. (1951) The antidiuretic response and excretion of pituitary (posterior lobe) extract in man with reference to the action of nicotine. Br. 7. Pharmac. Chemother. 6, 471.

Burn, H. J., Truelove, L. H. \& BURn, I. (1945) Antidiuretic action of nicotine and of smoking. Br. med. $\mathcal{F} . \mathrm{i}, 403$.

Caldeyro-Barcia, R. \& Heller, H. (Eds.) (1961) Oxytocin: Proceedings of an International Symposium held in Montevideo, 1959, pp. 393-399. Pergamon Press, Oxford.

Coutinho, E. M., Maia, H. \& Filxo, J. A. (1970) Response of the human Fallopian tube to adrenergic stimulation. Fert. Steril. 21, 590.

De Allende, F. L. C., Shorr, E. \& Hartman, G. G. (1945) A comparative study of the vaginal smear cycle in rhesus monkey and the human. Contr. Embryol. 31, 3.

Dyball, R. E. (1968) The effects of drugs on the release of vasopressin. Br. F. Pharmac. Chemother. 33, 329.

ERSPamer, V. (1961) Recent research in the field of 5-hydroxytryptamine and related indolealkylamines. Fortschr. Arzneimit. Forsch. 3, 151.

Garretr, W. J. (1958) The action of 5-HT on the human uterus. Archs int. Pharmacodyn Ther . 117, 435.

Hansson, E. (1964) In: Symposium on tobacco alkaloids and related compounds, p. 231. Ed. U. S. von Euler. Pergamon Press, New York.

Hansson, E., Masouko, D. T. \& Glark, W. G. (1964) Effect of nicotine on catecholamine and serotonin levels in vivo. Archs int. Pharmacodyn. Thér. 149, 153.

NERI, A. \& ECKERLING, B. (1969) The influence of nicotine and adrenaline (epinephrine) on uterotubal insufflation test (Rubin text). Fert. Steril. 20, 818.

Neri, A., Marcus, S. L. \& Fuchs, F. (1972) Motility of the oviduct in the rhesus monkey. In vivo studies with and without intra-uterine contraceptive devices. Obstet. Gynec., N.Y. 39, 105.

TAYLOR, N. B. G. \& WALKER, J. M. (1951) Antidiuretic substance in human urine after smoking. 7 . Physiol., Lond. 113, 412.

Thompson, J. H., Spezia, C. A. \& Angulo, M. (1969) The release of intestinal serotonin in rats by nicotine. F. Am. med. Ass. 207, 1083.

WALKER, J. M. (1949) The effect of smoking on water diuresis in man. Q. $\mathcal{~ l l ~ M e d . , ~ N . s . ~ 1 8 , ~} 51$.

Williams, E. D. (1965) 5-Hydroxytryptamine and antagonists. In: The Pharmacological Basis of Therapeutics. Eds. L. S. Goodman and A. Gilman. Macmillan, New York. 